\title{
Maintenance of stellite and tungsten carbide saw tips: respiratory health and exposure-response evaluations
}

\author{
Susan M Kennedy, Moira Chan-Yeung, Steve Marion, John Lea, Kay Teschke
}

\begin{abstract}
Objective-To study exposure to cobalt and chromium in saw maintenance rooms and test respiratory health among saw filers at lumber mills. Hard-metal lung disease is associated with cobalt in the manufacture of tungsten carbide tools; recently it has also been reported among tool maintenance workers. Lumber mills often use saws tipped with tungsten carbide or with a newer alloy, stellite (containing more cobalt, as well as chromium).
\end{abstract}

Methods-A cross sectional study of 118 saw filers at eight lumber mills was carried out that included a standardised questionnaire, spirometry, personal air sampling, and examination of tasks every 10 minutes (by observation). Comparison data were from a study of bus mechanics tested with similar methods.

Results and Conclusion-Cobalt exposure was associated with tungsten carbide grinding but not with stellite grinding. Chromium exposure was associated mainly with stellite welding. Saw filers had a twofold increase in phlegm and wheeze $(P<0.01)$ and $a$ threefold increase in cough, phlegm, and wheeze related to work $(P<0.001)$, but no increase in breathlessness. Stellite welding was associated with a significant increase in nasal symptoms and cough related to work and a small decrease in airflow (forced expiratory volume in one second/forced vital capacity $\left(F E V_{1} l\right.$ FVC\%), $P<0.05)$. Saw filers wet grinding with tungsten carbide had significant reductions in forced expiratory lung volumes $\left(F E V_{1}\right.$ and FVC, $\left.P<0.05\right)$ and were significantly more likely to have $\mathrm{FEV}_{1}$ and FVC values in the abnormal range. Cobalt exposure (in wet grinding) and duration of work that involved tungsten carbide grinding were both associated with significant reductions in $F E V_{1}$ and FVC. Average cobalt exposures in this study were about $5 \mu \mathrm{g} / \mathrm{m}^{3}$, well below the currently accepted permissible concentration, which suggests that the current workplace limit for cobalt may be too high.

\section{(Occup Environ Med 1995;52:185-191)}

Keywords: hard-metal lung disease; cobalt; tungsten carbide
Hard-metal lung disease occurs in workers exposed to cobalt in association with tungsten carbide (hard-metal) ${ }^{12}$ and in other metal working processes that involve exposure to cobalt, such as diamond polishing. ${ }^{3}$ The disease is an interstitial pneumonitis characterised by radiographic infiltrates, reduced diffusing capacity and lung volume, ${ }^{4}$ and a histology of fibrosing alveolitis with unusual multinucleated giant cells. ${ }^{5}$ Prevalence of about $1 \%$ is generally reported although some studies suggest higher rates. ${ }^{46}$ Fatal cases have been reported, ${ }^{7}$ and the predictors of fatality are not clear. Also, cobalt is known to cause occupational asthma ${ }^{18}$ and asthma like symptoms. ${ }^{2}$

Most studies of hard-metal lung disease in association with tungsten carbide have been limited to the tool manufacturing industry. We are aware of only one recent report of four cases of hard-metal lung disease among workers who use or maintain these tools. ${ }^{9}$ We report here results from a study of saw filers, who maintain saws in lumber mills.

Saw blades in lumber mills are generally made of hardened steel, but the cutting tips are often composed of specialty compounds welded or soldered to the saw body. In the past two decades, soldered tungsten carbide tips have become widely used. Tungsten carbide is a sintered metal composite with cobalt (from $3-30 \%$ ) as the binder for the tungsten carbide and other trace metals. ${ }^{10}$ More recently, saw tips have been welded with a superalloy, stellite (Deloro Stellite, Belleville, Ontario). In this alloy, cobalt (50-60\%), chromium (30-35\%), and other trace metals are heated above their melting points to create prealloyed powder, which is mixed with an organic binder before final sintering. ${ }^{10}$ Some saw filers also sharpen chipper knives that are predominantly iron (85-90\%), but also contain some chromium (8-9\%). ${ }^{11}$ In lumber mills in British Columbia, Canada, neither tungsten carbide nor stellite tips are universally used, although many mills use one or the other, and some use both.

Depending on the saw type and the process, saws in the lumber industry are used for only a few work shifts and then require sharpening. Saw filers perform a variety of tasks including removing saws from production lines, transferring them to the filing room for maintenance, and reinstalling saws into production. The maintenance work involves setting up and operating machinery to solder or weld new tips to the saw body, grinding and sharpening tips, and occasionally 
soldering and welding tips manually. Grinding and sharpening often requires lubrication with soluble machining fluids. Also, tasks for quality control and safety assurance of the saw bodies are performed. Although workers with different levels of training and seniority perform some of these tasks preferentially to others, no saw filers are engaged in grinding for an entire shift.

This report describes the results of a survey of respiratory health among saw filers in eight volunteer lumber mills in coastal British Columbia. Our principal objective was to determine whether or not these workers were exposed to excessive concentrations of cobalt or chromium, and if so, to evaluate the determinants of exposure; the respiratory health assessment was conducted as a pilot survey only. It should be noted that the study design (volunteer mills) does not ensure a representative picture of the entire industry, and that the sample size was not expected to be sufficient to detect clinically relevant cases of hard-metal lung disease. Results from the exposure evaluation are reported separately. ${ }^{12}$

\section{Methods}

\section{PARTICIPANTS}

Saw filers were identified from lists provided by the management at each mill. Each eligible participant (all men) was contacted by letter and invited to participate. Participation was entirely voluntary and each participant signed a "consent to participate" form before the tests, after having the aims and objectives of the study explained to him. The study protocol was approved by the University of British Columbia Committee on Ethics in Research Involving Human Subjects.

\section{EXTERNAL COMPARISON POPULATION}

As this was a pilot study, no external comparison population was included in the protocol. For some analyses comparisons were made with results obtained from bus mechanics studied by us in December 1990 with the identical respiratory symptom questionnaire and pulmonary function testing procedures and equipment. The technicians and interviewers for both studies were all trained by the same study coordinator. This group was studied due to their concern about past use of asbestos products. Results indicated that there was little or no impairment of health among the bus mechanics. Therefore, comparison of results from the saw filers with those from the bus mechanics is warranted for some analyses.

EXPOSURE MONITORING AND EVALUATION OF DETERMINANTS OF EXPOSURE

Details of the exposure assessment and evaluation of determinants of exposure are presented elsewhere. ${ }^{12} \mathrm{~A}$ brief summary is provided here. Each mill was visited four times at least one month apart from June to December 1991. On each test day all saw filers on the day shift were asked to wear a personal air sampler for a minimum of six hours, from which metal concentrations were quantified by inductively coupled argon plasma atomic emission spectrophotometry. A total of 278 air samples were obtained from 112 workers. Every worker in the saw filing room was involved in the exposure monitoring, regardless of his job tasks or suspected exposure potential. Coincident with air sampling, every 10 minutes, an industrial hygiene technician recorded each worker's specific activity, the name of the nearest operating machine, the distance between the breathing zone and the generation point of the contaminant, and whether or not the worker was smoking. As well as monitoring airborne exposure, 73 bulk samples of used coolant were obtained from lubricated grinding machines and analysed for metals.

More than half of the monitored values for cobalt and chromium in air were below the detection limit-that is, severe left censoring - and the remaining data did not meet tests of normality, even with log transformation. ${ }^{12}$ This presented a challenge for statistical analysis of the determinants of exposure. Details and rationale for the technique of analysis of the exposure data are presented elsewhere. ${ }^{12}$ Briefly, linear regression analyses were conducted with the cobalt or chromium concentration (original scale) as the dependent variable (with a value of half the detection limit entered for concentrations below the detection limit). Seven activity and 10 location variables were considered as the potential predictors. Both dichotomous (ever during the day $v$ never) and continuous (number of times observed during the day) versions of these variables were considered; however, the dichotomous versions were preferred in almost all cases. Modelling was done with generalised estimating equations and robust estimation of variance (thus taking into account both non-conformance with the equal variance assumption of ordinary least squares regression and the presence of repeated measures from the same worker). This approach has the advantage that each regression coefficient for a dichotomous variable represents the mean exposure for that activity or location.

\section{EVALUATION OF RESPIRATORY HEALTH}

An expanded version of the American Thoracic Society standard respiratory questionnaire ${ }^{13}$ was given by a trained interviewer. An occupational history, including a record of the duration and frequency for each of nine job tasks (including type of metal used and the use of machining fluids), was also obtained by the interviewer. Routine spirometry was carried out at the worksite by a trained technician with a 10 litre dry rolling seal spirometer ( $S$ and $M$ Instruments, Doylestown, PA, USA), according to standard American Thoracic Society procedures. ${ }^{14}$ Subjects were seated, wearing nose clips, and were required to perform at least three acceptable forced expiratory manoeuvres. The test was ended when a minimum plateau in expired volume of two seconds was 
reached. The highest value for forced expiratory volume in one second $\left(\mathrm{FEV}_{1}\right)$ forced vital capacity (FVC), and the midmaximal flow rate (MMF) from the blow with the largest sum of $\mathrm{FEV}_{1}$ and FVC were used for analysis. All volumes were corrected to body temperature, pressure, and saturation. Prediction equations used were those of Crapo and associates. ${ }^{15}$ Spirometry was performed just before starting work and at the end of the shift on each of the days that the workers wore the personal air samplers. Thus, each worker could have a minimum of one and a maximum of four days of measurements. Subjects were asked to refrain from smoking for at least one hour before each test.

For analyses of spirometric outcomes in which comparisons were made with the external control population, the average of the values before and after shift on the first day of testing of the saw filers was used. This was necessary to provide unbiased results that would be directly comparable to those from the control population, as the spirometric test in the control group was performed only once (randomly during the day, not before and after the shift).

\section{DATA HANDLING AND ANALYSIS}

Analyses were performed with SAS-PC statistical software (SAS Institute, Cary, NC, USA). Respiratory symptoms were defined as a positive answer to the questions: cough, "Do you usually have a cough?"; phlegm, "Do you usually bring up phlegm from your chest?"; wheeze, "Does your chest ever sound wheezy or whistling occasionally apart from when you have a cold?"; breathlessness, "Are you troubled by shortness of breath when you hurry on the level or walk up a slight hill?"; nasal symptoms, "Do you usually have an itchy, runny nose when you don't have a cold?". A work related symptom was defined as a symptom that was not present before starting work in the trade, and that improved when away from work on weekends or long holidays.

To evaluate the relation between tasks performed and respiratory health outcomes, each worker's job history was analysed to determine whether or not the worker's current (or past) work involved tungsten carbide grinding, tungsten carbide soldering, stellite grinding, stellite welding, and various other tasks.

Table 1 Frequency and duration of tasks within jobs in the saw filing trade (current and past)

\begin{tabular}{|c|c|c|c|}
\hline & $\begin{array}{l}\text { Ever } \\
\text { performing } \\
\text { this task } \\
(n)\end{array}$ & $\begin{array}{l}\text { Performing } \\
\text { this task in } \\
\text { current job } \\
(n)\end{array}$ & $\begin{array}{l}\text { Duration * of jobs } \\
\text { in which this task } \\
\text { was performed } \\
(y \text { (range) })\end{array}$ \\
\hline $\begin{array}{l}\text { Tungsten carbide wet grinding }(>10 \%) \\
\text { Tungsten carbide dry grinding }(>10 \%)\end{array}$ & $43 t$ & $\begin{array}{r}18 \\
9\end{array}$ & $6.9(0 \cdot 5-22)$ \\
\hline Stellite wet grinding $(>10 \%)$ & & 11 & \\
\hline Stellite dry grinding $(>10 \%)$ & $58 t$ & 18 & $3.8(0.5-10)$ \\
\hline Tungsten carbide soldering ( $>10 \%$ ) & 56 & 19 & $9 \cdot 6(0 \cdot 5-35)$ \\
\hline Stellite welding $(>10 \%)$ & 51 & 36 & $3.4(0.5-8)$ \\
\hline Chipper knife wet grinding & 40 & 15 & $8 \cdot 3(0 \cdot 3-35)$ \\
\hline
\end{tabular}

* Mean duration is shown only for those who have ever performed this task; $\nmid$ distinction between wet and dry grinding was not always possible for past jobs (therefore, except for the current job, these are taken together).
Time spent at these tasks, as well as details about the frequency of use of coolants was used to define six categories of potential exposure. Tungsten carbide wet grinding was defined as work in a job that involved grinding of tungsten carbide saw tips at least $10 \%$ of the time, for which at least $50 \%$ of the grinding was performed with a coolant. Tungsten carbide dry grinding was similarly defined, but required at least $50 \%$ of the grinding to be performed without a coolant. Stellite wet and dry grinding were defined similarly. Tungsten carbide soldering (or stellite welding) was defined as a job that involved soldering of tungsten carbide saw tips (or welding of stellite tips) at least $10 \%$ of the time. The number of years associated with work that involved such tasks was also calculated by summing all the years in which a worker's job satisfied one or more of these definitions.

\section{Results}

\section{DEMOGRAPHICS}

A total of 131 filing room personnel were eligible to participate; 118 took part $(90 \%)$. Reasons for lack of participation were sickness $(\mathrm{n}=3)$, refusal $(\mathrm{n}=3)$, and not being available during the test days $(n=7)$. The mean (range) age was $46 \cdot 7$ (31 to 62 ) years. The duration of employment averaged 21.3 years in the lumber mill and 15.5 years in the saw filing trade. Only $19 \%$ were current cigarette smokers; $59 \%$ were former smokers. The external comparison group was slightly younger (mean $44 \cdot 1$ years), and had about the same proportion of current smokers $(21 \%)$ but slightly fewer former smokers $(42 \%$, $P<0.01)$. There were no differences between these groups with respect to height, race, history of asthma, heart disease, or atopy.

\section{EXPOSURE EVALUATION}

Table 1 shows the specific jobs performed by these saw filers. Although all 118 workers were identified as saw filers, the number working at tasks in which exposure may have occurred was more limited. Also, although more workers reported more frequent current grinding or welding of stellite tips than tungsten carbide tips, the number of years in which tungsten carbide had been handled was greater than that for stellite. The proportion of the working day spent grinding or welding varied among the workers, but was seldom $>50 \%$ of the day.

The industrial hygiene assessment showed detectable cobalt concentrations in 62 of the 278 air samples collected. Of the samples above the detection limit, the mean (SD, maximum) cobalt concentration was 9 (20, 106) $\mu \mathrm{g} / \mathrm{m}^{3}$. The permissible eight hour concentration in our local jurisdiction is 100 $\mu \mathrm{g} / \mathrm{m}^{3}$ with a newly proposed reduction to $20 \mu \mathrm{g} / \mathrm{m}^{3}$. Factors that were significantly associated with airborne cobalt concentration were: working within five feet of a wet tungsten carbide grinding machine (coefficient: $4.7 \mu \mathrm{g} / \mathrm{m}^{3}, \mathrm{P}<0.05$ ), working within five feet of a dry tungsten carbide grinding machine 
(coefficient: $4.5 \mu \mathrm{g} / \mathrm{m}^{3}, \mathrm{P}<0.05$ ), and having a job title of knife grinder or head filer (both coefficients: $\left.-0.4 \mu \mathrm{g} / \mathrm{m}^{3}, \mathrm{P}<0.05\right)$. Together, these factors accounted for $24 \%$ of the variance in the cobalt air concentrations.

Chromium was detected in 105 of the air samples with a mean (SD, maximum) of 4 (9, 55) $\mu \mathrm{g} / \mathrm{m}^{3}$. The permissible concentration for chromium exposure is $50 \mu \mathrm{g} / \mathrm{m}^{3}$ for hexavalent chromium and $500 \mu \mathrm{g} / \mathrm{m}^{3}$ for other forms of the metal. (The analytical method used in this study did not distinguish the type of chromium present.) Work factors significantly associated with chromium exposure were: working within five feet of a stellite welding operation (coefficient $2.4 \mu \mathrm{g} / \mathrm{m}^{3}, \mathrm{P}<0.001$ ), working within five feet of a saw steel heating operation (coefficient $1.4 \mu \mathrm{g} / \mathrm{m}^{3}, \mathrm{P}<0.001$ ), and work as a knife grinder (coefficient $12 \cdot 2$ $\left.\mu \mathrm{g} / \mathrm{m}^{3}, \mathrm{P}<0.001\right)$. These factors accounted for $24 \%$ of the variance in this regression model.

The within subject variability in cobalt and chromium concentrations was evaluated in the 52 subjects with three or more measurements. The mean (range) coefficient of variation for cobalt was $102.5(8.4$ to 200.0$)$ and for chromium, 63.3 (0 to 199.9). No job title or mill showed a within subject variation significantly different from these mean values.

Cobalt concentrations in used coolant samples averaged $664 \mathrm{mg} / 1$ ( $\mathrm{n}=29$ samples) from tungsten carbide grinding machines, 76 $\mathrm{mg} / \mathrm{l}$ ( $\mathrm{n}=23$ samples) from stellite grinding machines, and $0.25 \mathrm{mg} / 1$ ( $n=18$ samples) from chipper knife grinding machines. Concentrations of chromium in these samples were $0.25 \mathrm{mg} / \mathrm{l}, 14.8 \mathrm{mg} / \mathrm{l}$, and $1.86 \mathrm{mg} / \mathrm{l}$ respectively.

\section{RESPIRATORY SYMPTOMS}

Compared with the external comparison group, saw filers reported about twice the rate of phlegm production $(22 \% \quad v \quad 11 \%)$ and wheeze $(23 \% v 10 \%$, both $\mathrm{P}<0.01)$, and about three times the rate of cough, phlegm, and wheeze related to work $(14,14,9 \% v$ $3,4,4 \%$ respectively, $\mathrm{P}<0.05)$. No significant difference was found between the groups for breathlessness or nasal symptoms.

Logistic regression analyses were per-

Table 2 Effect of work task and demographic variables on lung function variables $\ddagger$

\begin{tabular}{|c|c|c|c|c|}
\hline & $\begin{array}{l}F E V_{1} \\
\text { (l) }\end{array}$ & $\begin{array}{l}\text { FVC } \\
\text { (?) }\end{array}$ & $\begin{array}{l}M M F \\
(l / s)\end{array}$ & $\begin{array}{l}F E V, / F V C \\
(\%)\end{array}$ \\
\hline $\begin{array}{l}\text { Saw filer } v \\
\text { bus mechanic }\end{array}$ & +0.010 & +0.073 & $-0 \cdot 118$ & -0.88 \\
\hline $\begin{array}{l}\text { Tungsten carbide } \\
\text { wet grinding } \\
\text { (current job) }\end{array}$ & $-0.384^{\star}$ & $-0 \cdot 376^{\star}$ & $-0.607 \dagger$ & $-2 \cdot 21$ \\
\hline $\begin{array}{l}\text { Stellite welding } \\
\text { (current iob) }\end{array}$ & -0.016 & +0.158 & -0.334 & $-3 \cdot 27^{\star}$ \\
\hline $\begin{array}{l}\text { Age (y) } \\
\text { Smoking (pack-y): }\end{array}$ & $-0.032^{\star \star}$ & $-0.024^{\star \star}$ & $-0.061^{\star \star}$ & $-0 \cdot 26^{\star \star}$ \\
\hline $\begin{array}{l}\text { Current } \\
\text { Former }\end{array}$ & $\begin{array}{l}-0.006^{\star} \\
-0.005^{\star}\end{array}$ & $\begin{array}{l}+0.004 \\
-0.002\end{array}$ & $\begin{array}{l}-0.025^{\star \star} \\
-0.008^{\star}\end{array}$ & $\begin{array}{l}-0 \cdot 18^{\star \star} \\
-0.06^{\star \star}\end{array}$ \\
\hline $\begin{array}{l}\text { Tungsten carbide wet or dry } \\
\text { grinding, duration (y) }\end{array}$ & -0.007 & $-0.023 t$ & +0.023 & +0.22 \\
\hline
\end{tabular}

formed for each symptom, in which age, smoking, job (saw filer $v$ bus mechanic), and the work tasks (table 1) were included as predictors. The only work task that was a significant predictor for any symptom was stellite welding, associated with increased relative odds of 5.0 ( $95 \%$ confidence interval $(95 \%$ CI) 1.9 to 13.1 ) for nasal symptoms and 3.7 (95\% CI $1 \cdot 1$ to $12 \cdot 0)$ for work related cough. Inclusion of stellite welding in the regression model did not reduce the magnitude of the increased relative odds associated with saw filing in general (compared with bus mechanics), for any of the symptoms shown.

\section{ACUTE PULMONARY FUNCTION EFFECTS \\ DURING A SHIFT}

A total of 35 saw filers had a $\geqslant 5 \%$ drop in FEV $_{1}$ over the shift on at least one day and a $\geqslant 5 \%$ average change (over all test days) was seen in 12 workers. There were no significant relations found between the change in $\mathrm{FEV}_{1}$ over one workshift and any of the following: measured cobalt or chromium exposure (both log transformed and untransformed); number of saw changes; cigarette smoking; age; or working in a cedar mill (compared with a non-cedar mill). Participants with a history of asthma were significantly more likely to experience an increase in $\mathrm{FEV}_{1}$ over the work shift, compared with those with no such history ( $\mathrm{P}<0.05$, data not shown). A detailed case by case examination of the respiratory symptoms reported and the changes in lung function (and corresponding daily cobalt and chromium exposures) showed no obvious or suggestive cases of occupational asthma specific to cobalt or chromium.

\section{PULMONARY FUNCTION RESULTS}

No significant differences were found for $\mathrm{FEV}_{1}$ or FVC between saw filers as a group and the external comparison population, although saw filers had a lower average FEV $_{1} /$ FVC\% $^{2}(75.6 v 77.0, P<0.05)$ and MMF (3.25 $v 3.47 \mathrm{l} / \mathrm{s}, \mathrm{P}=0.06)$, after controlling for age, height, race, smoking, and amount smoked (pack-years).

Table 2 shows results from linear regression analyses for pulmonary function outcomes in which age, height, race, smoking, pack-years, history of childhood asthma, and the jobs (table 1) were included. Tasks significantly associated with lung function outcomes were wet grinding of tungsten carbide in the current job (associated with reduced $\mathrm{FEV}_{1}$, FVC, and MMF) and welding of stellite in the current job (associated with reduced $\mathrm{FEV}_{1} / \mathrm{FVC}$ ). The number of years spent in tungsten carbide grinding jobs (either wet or dry) was significantly associated with reduced FVC when current job tasks were not included in the model (not shown), but when current tungsten carbide wet grinding was taken into account years spent at this task became only marginally significant (table 2 ).

Table 3 shows odds ratios (ORs) (adjusted for age, race, history of childhood asthma, and smoking) for predictors of abnormal $\mathrm{FEV}_{1}$ and $\mathrm{MMF}\left(\mathrm{FEV}_{1}<80 \%\right.$ predicted and 
Table 3 Odds ratio * (95\% CI) as job task predictors of abnormal levels of lung function

\begin{tabular}{|c|c|c|}
\hline & $F E V_{1}<80 \%$ predicted & $M M F<60 \%$ predicted \\
\hline Current smoker & $2 \cdot 6(1 \cdot 0,7 \cdot 0)$ & $3 \cdot 1(1 \cdot 5,6 \cdot 5)$ \\
\hline Former smoker & $1.7(0.7,3.9)$ & $1 \cdot 1(0 \cdot 6,2 \cdot 0)$ \\
\hline $\begin{array}{l}\text { Saw filer } \\
\text { ( } v \text { bus mechanic) }\end{array}$ & $0.5(0.2,1 \cdot 3)$ & $0.9(0.5,1.8)$ \\
\hline $\begin{array}{l}\text { Tungsten carbide } \\
\text { wet grinding } \\
\text { (current job) }\end{array}$ & $6 \cdot 6(1 \cdot 7,24 \cdot 8)$ & $1.5(0.4,5.4)$ \\
\hline $\begin{array}{r}\text { Stellite welding } \\
\text { (current job) }\end{array}$ & $2 \cdot 9(0 \cdot 8,9 \cdot 8)$ & $2.3(0.8,6 \cdot 2)$ \\
\hline
\end{tabular}

ॠFrom logistic regression models, including age, history of childhood asthma, race, and all of the variables listed above.

Table 4 Linear regression models of exposure response relationst (lumber mill population only)

\begin{tabular}{|c|c|c|}
\hline & $F E V_{1}($ l) & $F V C(l)$ \\
\hline & (coefficient (SEM)) & (coefficient (SEM)) \\
\hline \multicolumn{3}{|l|}{ Model 1: } \\
\hline $\begin{array}{l}\text { Cobalt exposure } \\
\left(\mu \mathrm{g} / \mathrm{m}^{3}\right) \ddagger \\
\text { Model } 2:\end{array}$ & $-0.070(0.025)^{\star}$ & $-0.072(0.029)^{\star}$ \\
\hline $\begin{array}{l}\text { Tungsten carbide } \\
\text { grinding duration (y) } \\
\text { Model 3: }\end{array}$ & $-0.020(0.008)^{\star}$ & $-0.029(0.009)^{\star \star}$ \\
\hline $\begin{array}{l}\text { Cobalt exposure } \\
\left(\mu \mathrm{g} / \mathrm{m}^{3}\right) \ddagger\end{array}$ & $-0.055(0.027)^{\star}$ & $-0.042(0.031)$ \\
\hline $\begin{array}{l}\text { Tungsten carbide } \\
\text { grinding duration (y) }\end{array}$ & $-0.012(0.009)$ & $-0.022(0.011)^{\star}$ \\
\hline
\end{tabular}

MMF $<60 \%$ predicted). Wet grinding of tungsten carbide in the current job was associated with a sixfold increase in OR for $\mathrm{FEV}_{1}$ $<80 \%$ predicted. Stellite welding was associated with a twofold increased OR for both abnormal $\mathrm{FEV}_{1}$ and MMF (although this was not significant at the $P<0.05$ level). No other job task was significantly associated with these outcomes. It was not possible to carry out this type of analysis for abnormal FVC because the number of subjects with FVC $<80 \%$ predicted ( $n=4$, all long term ex-smokers) was too small to allow for stable statistical modelling. The unadjusted OR for abnormal FVC associated with wet tungsten carbide grinding in the current job was $5.3(95 \%$ CI 0.7 to 40.0 ) and for each decade of wet tungsten carbide grinding $5 \cdot 0$ (95\% CI $1 \cdot 1$ to $23 \cdot 9)$.

Several additional work factors were considered in these models but were not found to be associated with any of the health outcomes. These included working in a cedar mill (or duration of time in a cedar mill); average number of times each worker changed saws in the mill itself (representing potential for wood dust exposure); and duration of employment in the saw filing trade, with the current employer, and in saw milling.

As personal exposure monitoring in this study was limited to data collected on a maximum of four working days, and the within subject variation was extremely high, the measured personal exposure values collected on the study days were unlikely to provide reasonable quantitative estimates of each worker's average exposure over an extended period of time. Therefore, to perform limited quantitative exposure-response modelling, estimated cobalt (and chromium) exposures were assigned to each saw filer with the predicted cobalt (and chromium) exposure values from the analysis of determinants of exposure, according to their current job tasks. Only the analysis with respect to cobalt exposure was significant.

For this analysis, saw filers who did not perform tungsten carbide grinding were assigned the predicted background exposure $\left(0.77 \mu \mathrm{g} / \mathrm{m}^{3}\right)$, head filers and knife grinders were assigned the predicted (lower than average background) exposure of $0.33 \mu \mathrm{g} / \mathrm{m}^{3}$, and saw filers who performed tungsten carbide grinding in their current job were assigned the cobalt exposure associated with that task (5.6 $\mu \mathrm{g} / \mathrm{m}^{3}$ for wet grinding, $5.4 \mu \mathrm{g} / \mathrm{m}^{3}$ for dry grinding). Regression analyses were performed for pulmonary function outcomes, which included as predictors this estimated level of cobalt exposure, the difference between the estimated level of exposure and the average level of exposure for each participant, and the duration of employment in jobs that involved tungsten carbide grinding. Table 4 shows the results for $\mathrm{FEV}_{1}$ and FVC. (No significant relations were found between exposure and $\mathrm{MMF}$ or $\mathrm{FEV}_{1} / \mathrm{FVC} \%$.) Both level of cobalt exposure and duration of tungsten carbide grinding were significantly associated with reductions in $F E V_{1}$ and FVC when these variables were included separately in the models (models 1 and 2). When both variables were analysed together (model 3 ), coefficients for each decreased; $\mathrm{FEV}_{1}$ was slightly more likely to be associated with level of exposure, whereas FVC was slightly more likely to be associated with duration of exposure.

When the difference between the estimated exposure and the actual average measured exposure was included in these models, the only change found was that the coefficients for estimated exposure became slightly more negative and had a slightly higher level of significance in every case. The coefficient for the difference between the two exposure values was close to 0 and not significant. These results are not shown.

Finally, when separate cobalt exposures were included for wet grinders and all others, the wet grinding cobalt exposure term remained significant and about the same size, whereas the exposure term for other workers became non-significant and approached 0 .

\section{Discussion}

These results suggest that grinding tungsten carbide tools, especially in the presence of a coolant, may be associated with significant reductions in measured lung capacity $\left(\mathrm{FEV}_{1}\right.$ and FVC). This reduction did not seem to be accompanied by breathlessness in workers currently employed in the volunteer mills. Stellite welding was associated with symptoms of irritation (nasal symptoms and cough) and small reductions in airflow rates (specifically $\mathrm{FEV}_{1} / \mathrm{FVC} \%$ and MMF). These two 
exposures and combination of outcomes are discussed separately.

It is noteworthy that despite a high cobalt concentration in stellite, this was not associated with increased airborne cobalt concentrations or in increased cobalt in the coolant fluid from machines on which stellite tips were ground. Furthermore, stellite grinding was not associated with decreases in lung volumes or with increases in respiratory symptoms.

Stellite welding was associated with increased nasal symptoms and slight decreases in the $\mathrm{FEV}_{1} / \mathrm{FVC}$ ratio. These effects may be the result of chromium exposure as both nasal symptoms and reductions in airflow have been associated with airborne chromium exposure in other studies. ${ }^{16}$ These effects were not found, however, in association with chipper knife grinding, the task with the highest measured cobalt exposure. One explanation is that the form of cobalt may differ between these tasks. Exposure to hexavalent chromium has been found in association with stainless steel welding $^{17}$; thus it is possible that stellite welding could also produce this form of chromium (whereas the chipper knife grinding may not generate sufficient heat to oxidise the chromium).

Tungsten carbide grinding in these mills was associated with increased airborne cobalt concentrations and with very high concentrations of cobalt in the coolant from tungsten carbide wet grinding machines. Workers who performed this task, particularly those who used coolant most of the time, had significant reductions in both $\mathrm{FEV}_{1}$ and FVC compared with other saw filing tradesmen.

Airborne cobalt exposures were similar for dry and wet grinding, but significant $\mathrm{FEV}_{1}$ and FVC reductions were found only in association with predominantly wet grinding. One might conclude that the coolant itself is the aetiological agent. Although machining coolants have been implicated in pulmonary function decrements in other studies, ${ }^{18}$ this is an unlikely explanation here as wet grinding of the other metals - for example, stellite and mild steel-with the same coolants, did not result in reductions in lung function. The grinding fluid may, however, have contributed to a change in the form or toxicity of the cobalt. Cobalt from dry grinding may remain in elemental form, whereas cobalt from wet grinding may be present as (potentially more toxic) cobalt ion in solution; cobalt may have an enhanced toxic potential when present in coolant due to an adjuvant effect of the coolant; or additional exposure from ingestion or skin absorption may occur more often in association with wet grinding. Our study cannot distinguish between these possible mechanisms for the difference in physiological effect of wet $v$ dry grinding.

Two previous studies have shown wet grinding of tungsten carbide in tool manufacturing to be associated with an increased rate of hard-metal disease and with reductions in diffusing capacity, ${ }^{219}$ despite the fact that wet grinders were not the group most highly exposed.

Hard-metal disease is generally characterised by both reduced FVC and breathlessness. Although a strong exposure-response relation was seen in this study, the values for lung function were generally in the clinically normal range; thus it is not surprising that there was no obvious increase in breathlessness. It is not possible to determine, from this study, whether or not there will be further deterioration in these workers to the stage of symptomatic hard-metal lung disease, or whether the results from these volunteer mills are representative of the industry as a whole.

Although at the time this study started, we were not aware of any cases of hard-metal lung disease among saw filers in lumber mills in British Columbia, after conclusion of this study, we learned of a recent fatal case of hard-metal lung disease in a 50 year old saw filer from a different British Columbian lumber mill (A Churg, personal communication). This confirms the potential for serious pathology among workers in this trade.

In this study, the average cobalt exposure associated with significant reductions in lung volume was well below the allowable concentrations of most jurisdictions and even well below the newly recommended 1994 permissible concentration of the American Conference of Governmental and Industrial Hygienists. Similar results of significant reductions in $\mathrm{FEV}_{1}$ and FVC associated with low cobalt exposure have been reported by Nemery and colleagues in a study of diamond polishers. $^{20}$ The average airborne cobalt exposure in the high exposure workshops in that study was $10 \cdot 2 \mu \mathrm{g} / \mathrm{m}^{3}$. Also similar to our results was their finding of increased symptoms of cough and upper airway irritation but no significant increase in breathlessness.

Our results suggest that a permissible concentration for cobalt exposure (at least for cobalt in association with tungsten carbide grinding) should be set at a value considerably lower than the currently recommended $20 \mu \mathrm{g} / \mathrm{m}^{3}$. Based on our findings alone, this conclusion is most relevant for cobalt associated with coolants and is dependent on the assumption that the average cobalt concentration measured in the eight study mills is a reasonable reflection of the exposures that would have been found in these mills over the past several years. As the induction period for hard-metal lung disease can vary from as little as one up to 30 years from first exposure, ${ }^{14}$ both recent and past exposures may contribute to the disease process. In the absence of information to evaluate recent and distant past exposures, it would be prudent to assume that the exposures measured in this study are not significantly different from past exposures in these mills. This, together with the previously published evidence of similar exposure-response relations in a different industry, ${ }^{20}$ argue in favour of establishing a permissible concentration for cobalt close to the average values found in these mills- 
for example, a time weighted average of $5 \mu \mathrm{g} / \mathrm{m}^{3}$. The exposure measurements made in this study show that cobalt from tungsten carbide grinding can be successfully controlled to this air concentration.

1 Davison AG, Haslam PL, Corrin B, Coutts II, Dewar A, Riding WD, et al. Interstitial lung disease and asthma in hard-metal workers: bronchoalveolar lavage, ultrastructural and analytical findings and results of bronchial provocation tests. Thorax 1983;38:119-28.

2 Sprince NL, Oliver LC, Eisen EA, Greene RE, Chamberlain RI. Cobalt exposure and lung disease in tungsten carbide production. A cross-sectional study of tungsten carbide production. A cross-sectional study of
current workers. Am Rev Respir Dis 1988;138:1220-6.

3 Demedts M, Gheysens B, Hagels J, Verbeken E, Lauweryns J, Van den Eeckhout A, et al. Cobalt lung in Lauweryns J, Van den Eeckhout A, et al. Cobalt lung in
diamond polishers. Am Rev Respir Dis 1984;130:130-5.

4 Fischbein A, Jiin-Chyuan JL, Solomon SJ, Horowitz S, Hailoo W, Miller A. Clinical findings among hard metal workers. Br f Ind Med 1992;49:17-24.

5 Ohori NP, Sciurba FC, Owens GR, Hodgson MJ, Yousem SA. Giant-cell interstitial pneumonia and hard-metal pneumoconiosis. Am ₹ Surg Pathol 1989;13:581-7.

6 Meyer-Bisch C, Pham QT, Mur JM, Massin N, Moulin JJ, Teculescu D, et al. Respiratory hazards in hard metal workers: a cross sectional study. Br F Ind Med 1989; w6:302-9.

7 Nemery B, Nagels J, Verbeken E, Dinsdale D, Demedts $M$. Rapidly fatal progression of cobalt lung in a diamond M. Rapidly fatal progression of cobalt lung in a
polisher. Am Rev Respir Dis 1990;141:1373-8.

8 Gheysens B, Auxerx J, Van den Eeckhout A, Demedts M. Cobalt-induced bronchial asthma in diamond polishers. Chest 1985;88:740-4.
9 Barnhart S, Daniell W, Stebbins A, Rosenstock L. Occurrence of hard metal pneumoconiosis at exposure levels below the permissible exposure limit. Am Rev Respir Dis 1991;143:A263.

10 Bayer AM, Vasco T, Walton LR. Wrought tool steels. In: Metals handbook, $10^{\text {th }}$ ed. Vol. 1. Properties and selection: irons, steels, and high-performance alloys. Ohio: American Society for Metal, 1990:757-63.

11 Material safety data sheet for chipper knife A 8 modified. Delta, British Columbia: Simonds Industries, 1992.

12 Teschke K, Marion SA, van Zuylen MJA, Kennedy SM Maintenance of stellite and tungsten carbide saw tips: determinants of exposure to cobalt and chromium. $A m$ Ind Hyg Assoc $\mathcal{F} 1995$ (in press).

13 American Lung Association. Recommended respiratory diseases questionnaire for use with adults and children in epidemiological research. Am Rev Respir Dis 1978;118:7.

14 American Thoracic Society. Standardization of spirometry-1987 update. Am Rev Respir Dis 1987;136: try-1987

15 Crapo RO, Morris AH, Gardner RM. Reference spirometric values using techniques and equipment that meet American Thoracic Society recommendations. Am Rev Respir Dis 1981;123:659-64

16 Schneider WD, Grund W, Schmidt G, Wiesnerchromium W. Respiratory diseases in welders on stainless steel and/or aluminium - a cross sectional study. Eur $\mathcal{Y}$ Respir Dis 1982;62:179-80.

17 Gray CN. Hexavalent chromium in welding fume and the role of ozone. Ann Occup Hyg 1987;31:269-70.

18 Kennedy S, Greaves IA, Kriebel D, Eisen EA, Smith TJ, Woskie SR. Acute pulmonary responses among automobile workers exposed to aerosols of machining fluids. $\mathrm{Am}$ fl Ind Med 1989;15:627-41.

19 Sjogren I, Hillerdal G, Anderson A, Zetterstrom O. Hard metal lung disease: importance of cobalt in coolants. metal lung disease: im
Thorax 1980;35:653-9.

20 Nemery B, Casier P, Roosels D, Lahaye D, Demedts $M$. Survey of cobalt exposure and respiratory health in diamond polishers. Am Rev Respir Dis 1992;145:610-6. 